\title{
Analysis of triazines by reversed electroosmotic flow capillary electrophoresis-electrospray mass spectrometry
}

\author{
Cheng-Yuan Tsai, Yet-Ran Chen, Guor-Rong Her* \\ Department of Chemistry, National Taiwan University, Taipei, Taiwan
}

Received 5 January 1998; received in revised form 28 April 1998; accepted 28 April 1998

\begin{abstract}
Normal and reversed electroosmotic flow (EOF) capillary electrophoresis (CE) has been studied for the analysis of eight triazine herbicides. Reversed EOF CE, dynamically modified with cetyltrimethylammonium bromide (CTAB), provided better separation than normal CE. All eight triazines were baseline resolved with the use of $50 \mathrm{~m} M$ ammonium acetate and $0.7 \mathrm{~m} M \mathrm{CTAB}$ as the running buffer. The method of sheath liquid was used in the on-line coupling of $\mathrm{CE}$ with electrospray mass spectrometry. The composition of sheath liquid was found to be critical in the coupling of reversed EOF CE with MS. The resolution obtained in CE-UV can be preserved in CE-MS if the composition of the sheath liquid is similar to the running buffer. () 1998 Elsevier Science B.V. All rights reserved.
\end{abstract}

Keywords: Electroosmotic flow; Triazines; Pesticides

\section{Introduction}

Triazine derivatives are among the most important selective herbicides. Triazine herbicides are usually applied as pre and post-emergent weed control to improve the quality of agricultural products. These herbicides are 1,3,5-triazine substituted at the 2, 4 and 6 positions. The substituent at the 2 position gives each triazine its specific selectivity. The 4 and 6 positions are substituted with different aminoalkyl groups.

Due to their wide use and relatively high resistance, knowledge of triazines in the environment, both qualitatively and quantitatively, is of great importance to environmental and water control [1]. Analytical techniques including high-performance

\footnotetext{
*Corresponding author. Fax: +886-2-23638058; e-mail: grher@mail.ch.ntu.edu.tw
}

liquid chromatography (HPLC) [2,3], gas chromatography (GC) [4], ion chromatography (IC) [5], thin-layer chromatography (TLC) [6], gas chromatography-mass spectrometry (GC-MS) [7-9], and liquid chromatography-mass spectrometry (LCMS) [10,11] have been used for the analysis of triazines. Recently, mainly because of its superior separation efficiency, several groups have explored the potentials of capillary zone electrophoresis (CZE) $[1,12]$ and micellar electrokinetic chromatography (MEKC) [13-20] for analysis of triazines.

MS is compatible with capillary electrophoresis (CE) with respect to the sample amount and is one of the most powerful detection methods for identification of separated analytes. Among the ionization techniques, electrospray ionization (ESI) is often considered the most suitable technique for on-line coupling of CE with MS. MEKC often provides better resolution than CZE in the analysis of triazine 
herbicides [15], the combination of MEKC with ESI-MS is, however, generally considered difficult because of the use of high concentration surfactants in the running buffer. Recently, Lee et al. reported the use of partial filled MEKC-ESI-MS for the analysis of four triazines [19]. In this paper, we report the results of using reversed electroosmotic flow (EOF) CE-UV and reversed EOF CE-ESI-MS for the analysis of eight triazines.

\section{Experimental}

\subsection{Chemicals}

Methanol, ethanol, 2-propanol, ammonium acetate, acetic acid, and trifluoroacetic acid were of chromatographic grade from J.T. Baker (Phillipsburg, NJ, USA). Triazine standards were obtained from Supelco (Bellefonte, PA, USA). A stock standard solution of triazine mixture was prepared in methanol and stored in a refrigerator. Deionized (18 $\mathrm{M} \Omega$ ) water (Milli-Q water system, Millipore, Bedford, MA, USA) was used in the preparation of the samples and buffer solution. Cetyltrimethylammonium bromide (CTAB) was purchased from Sigma (St. Louis, MO, USA).

\subsection{Capillary electrophoresis}

The CE apparatus was constructed in the laboratory and had been described elsewhere [21-23]. The fused-silica capillary columns (Polymicro Technologies, Phoenix, AZ, USA) were $80 \mathrm{~cm}(70 \mathrm{~cm}$ to detector $\times 50 \mu \mathrm{m}$ I.D. $\times 375 \mu \mathrm{m}$ O.D. A small area of the polyimide coating was burned off to form a window for UV detection. On-column detection was performed on an UV detector (UV-C, Rainin, Emeryville, CA, USA) operated at $230 \mathrm{~nm}$. Before use the capillary columns are washed with $0.1 \mathrm{M}$ $\mathrm{NaOH}$ and water followed by running buffer. The capillary was then equilibrated with running buffer for $20 \mathrm{~min}$.

\subsection{Mass spectrometry}

A VG platform single quadrupole mass spectrometer (Micromass, Altrincham, UK) equipped with a
CE interface was used for this study. The interface utilizes a triaxial flow arrangement whereby the CE elute is mixed with a suitable sheath liquid at the probe tip and then nebulized using $\mathrm{N}_{2}$ gas. The high voltage applied on the buffer reservoir was $+20 \mathrm{kV}$ and $-20 \mathrm{kV}$ in normal and reversed EOF CE-MS, with the $3.5-\mathrm{kV}$ ESI voltage applied on the outlet of the separation column. The potential difference during the analysis of triazines was about $16.5 \mathrm{kV}$ and $23.5 \mathrm{kV}$ for normal and reversed EOF CE, respectively. For electrical contact at the tip of the interface, a sheath liquid was delivered at a flow-rate of $10 \mu \mathrm{l} / \mathrm{min}$ by a Model H-74900-00 syringe pump (Cole-Parmer, Niles, IL, USA). In order to obtain maximum sensitivity, the silica tip was protruded 0.2 $\mathrm{mm}$ outside the stainless steel needle. The mass spectrometer was operated in the positive-ion mode and the data were collected at selected-ion monitoring mode ( $0.2 \mathrm{~s}$ dwell time, 0.2 mass unit span).

\section{Results and discussion}

\section{1. $C E-U V$ analysis of triazines}

Eight triazines, differing minimally in structure and properties, were studied by CE. The structures of these chlorotriazines, thiomethyltriazines and methoxytriazine are shown in Fig. 1. Various buffer systems were tested in the normal EOF CE study. The best result was obtained with $50 \mathrm{mM}$ ammonium acetate at $\mathrm{pH} 4.5$ as the running buffer (Fig. 2a). Only four peaks were observed. Co-injection of triazine standards suggested the elution order of prometon, terbutryne, ametryn/prometryn/simetryn, and simazine/atrazine/propazine, respectively. The third and fourth peaks were broader than others indicating partial separation of the coeluted triazines. The separation efficiency increased somewhat with the addition of $\gamma$-cyclodextrin into the buffer system. Unfortunately, the eight triazines were still not baseline resolved (data not shown).

Control of the electroosmotic mobility is very important for improving the separation and shortening the analysis time in CE. The rate of EOF may be altered by varying the composition of the employed buffer system. The addition of cationic surfactants in background electrolyte has a large 
<smiles>[R5]Nc1nc(Cl)nc(N([R6])[B])n1</smiles>

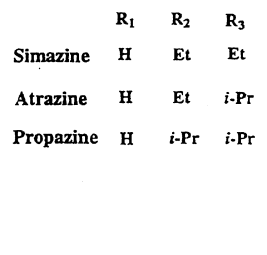<smiles>[R5]Nc1nc([As])nc(N([R2])[B])n1</smiles>

\begin{tabular}{llll}
$\mathbf{R}_{\mathbf{1}}$ & $\mathbf{R}_{\mathbf{2}}$ & $\mathbf{R}_{3}$ \\
\hline metryn & $\mathbf{H}$ & $\mathbf{E}$ &
\end{tabular} Prometryn $\mathrm{H} \quad i-\mathrm{Pr} \quad i-\mathrm{Pr}$ Terbutryne $\mathrm{H} \quad \mathrm{Et} \quad \boldsymbol{t}$-Bu Simetryn H Et Et<smiles>[R5]Nc1nc(OC)nc(N([R7])[R])n1</smiles>

Fig. 1. Structures of triazines. Et $=$ Ethyl; $i-\mathrm{Pr}=$ isopropyl; $t-\mathrm{Bu}=$ tert.-butyl.

effect on electroosmotic mobility. On increasing the concentration of cationic surfactant, the electroosmotic mobility decreases finally to the point that the direction of the EOF is reversed [24]. Terabe et al. [25] first reported the use of CTAB to modify the EOF. The CTAB surfactant formed a positively charged layer on the inner wall of the capillary and induced the reversal of EOF. Since then, this dynamic coating method has been applied to the separation of vitamins [26], DNA [27], and phenol [28].

The reversed EOF technique was adopted for the analysis of triazines and the resolution was found to be much better than normal CE. The electropherogram obtained with a concentration of $50 \mathrm{~m} M$ ammonium acetate and $0.7 \mathrm{~m} M$ CTAB at $\mathrm{pH} 3.85$ is shown in Fig. 2b. All eight triazines were baseline resolved. Because the direction of EOF is changed, the elution order of triazines is in general reverse to that of normal CE. By comparing the Fig. 2a and b, migration times of triazines in normal and reversed $\mathrm{CE}$ are slightly different. However, the migration window of the reversed EOF CE is significantly larger than the normal CE. Besides the change in the direction of EOF, the partition of triazines with

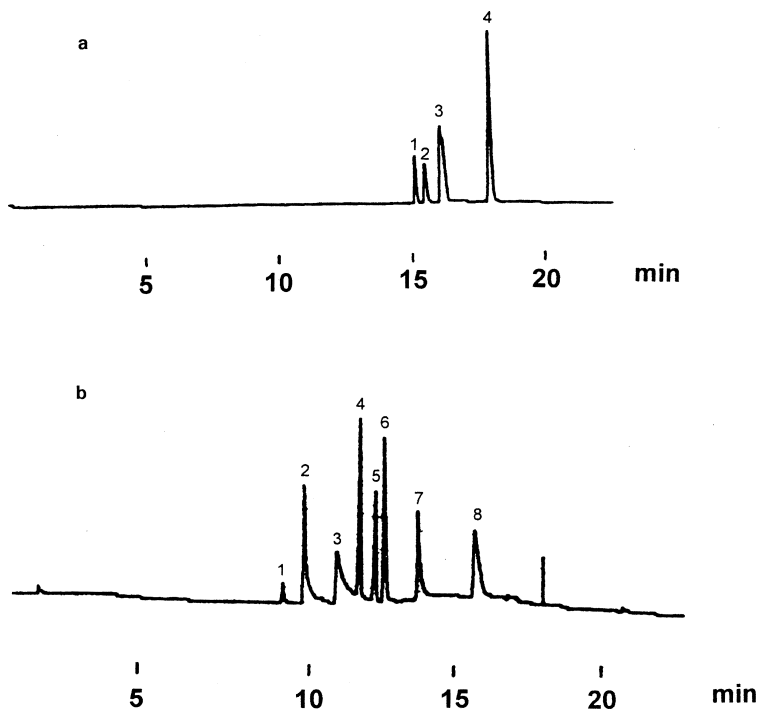

Fig. 2. Electropherogram of triazines by normal CE. An 80 $\mathrm{cm} \times 50 \mu \mathrm{m}$ I.D. fused-silica capillary tubing was used with 50 $\mathrm{m} M$ ammonium acetate at $\mathrm{pH} 4.5$ as the running buffer. The potential was $+20 \mathrm{kV}$ and the detection wavelength was $230 \mathrm{~nm}$. Sample $(50 \mu \mathrm{g} / \mathrm{ml})$ was injected electrokinetically at $10 \mathrm{kV}$ for 10 s. Peaks were assigned as (1) prometon; (2) terbutryne; (3) prometryn, ametryn, simetryn; (4) propazine, atrazine, simazine. (b) Electropherogram of eight triazines by reversed EOF CE. An $80 \mathrm{~cm} \times 50 \mathrm{~mm}$ I.D. fused-silica capillary tubing was used with 50 $\mathrm{m} M$ ammonium acetate containing $0.7 \mathrm{~m} M$ CTAB at $\mathrm{pH} 3.85$ as the running buffer. The potential was $-20 \mathrm{kV}$ and the detection wavelength was $230 \mathrm{~nm}$. Sample $(50 \mu \mathrm{g} / \mathrm{ml})$ was injected electrokinetically at $10 \mathrm{kV}$ for $10 \mathrm{~s}$. Peaks were assigned as (1) simazine; (2) atrazine; (3) propazine; (4) simetryn; (5) ametryn; (6) prometon; (7) prometryn; (8) terbutryne.

CTAB surfactants through hydrophobic interaction possibly contributes to the significant enhancement in separation resolution obtained with reversed EOF CZE.

\section{CE-MS analysis of triazines}

Triazines can be easily detected by positive ESI. The mass spectra are characterized with protonated molecular ion with little fragmentation. More structural information can be obtained if the spectra are acquired under in source collision-induced dissociation (CID) [29-31]. Typical ESI and in source CID mass spectra of triazines are shown in Fig. 3.

In the coupling of CE with ESI-MS, the selection 
(a)

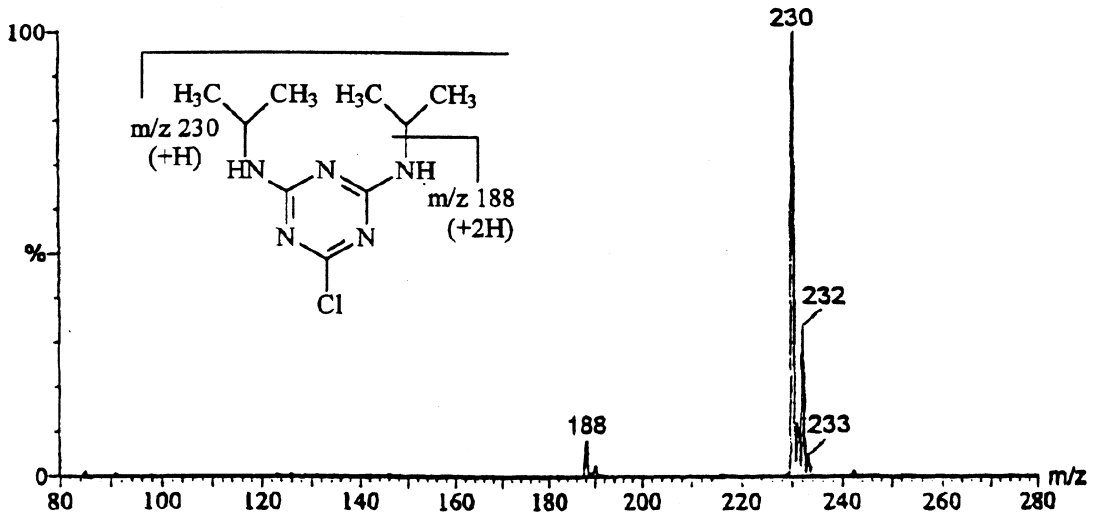

(b)

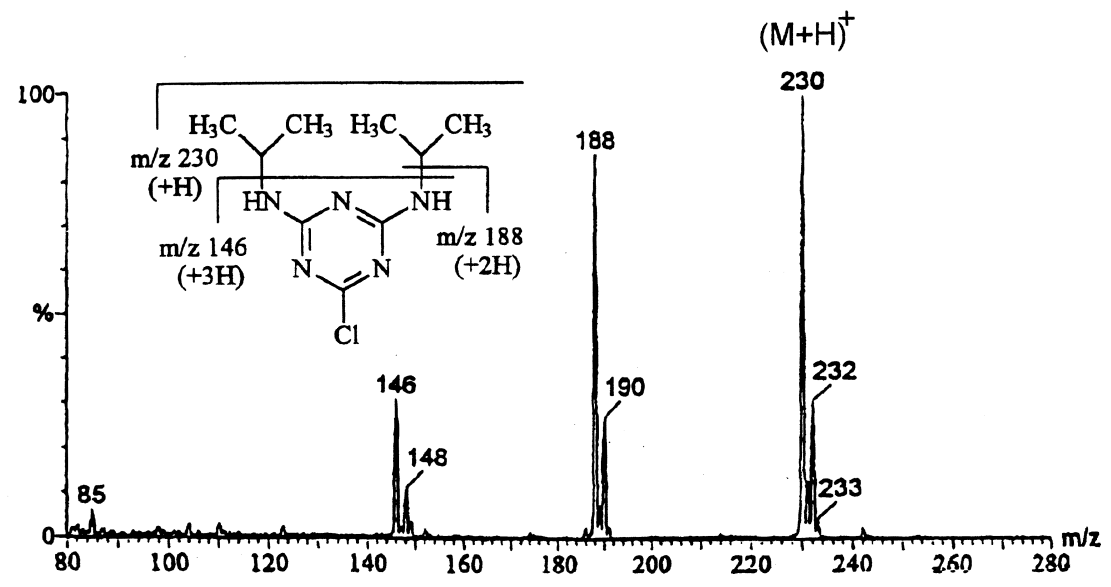

Fig. 3. Positive ESI (a) and in source CID (b) mass spectra of propazine.

of the buffer system should consider not only the CE resolution but also the compatibility of the buffer with ESI. In normal CE-ESI-MS analysis, ammonium acetate proved to be an appropriate buffer regarding the separation of triazines as well as the sensitivity and stability of ESI-MS. However, high concentration of buffer might compete with the analytes in ESI process [32,33] and resulting in poor sensitivity. Sensitivity and ion current stability under positive ESI condition were studied under different buffer concentrations. In the experiment, a $5 \mu \mathrm{g} / \mathrm{ml}$ atrazines solution was electroosmotically infused through the silica capillary and then mixed with sheath liquid $(10 \mu \mathrm{l} / \mathrm{min})$ at the tip of the CE probe.
The results showed that the sensitivity decreased as buffer concentration increased. Although lower buffer solution concentration provided better sensitivity, the CE resolution dropped significantly. This result suggested that the higher ionic strength was good for separation resolution but not for sensitivity. To maintain the $\mathrm{CE}$ resolution and also keep appropriate sensitivity, $50 \mathrm{~m} M$ ammonium acetate was used throughout the normal CE-MS study.

Sheath liquid was passed between the separation and the stainless capillary column and then mixed with the running buffer at the tip of the probe. To achieve optimum sensitivity, the separation column was extended about $0.2 \mathrm{~mm}$ beyond the tip of the 
stainless capillary column. If the silica tubing protruded too far to make a good electrical contact, the sensitivity dropped dramatically.

The composition of sheath liquid was found to affect ESI sensitivity. A solution of methanol-water (80:20) containing $0.1 \%$ trifluoroacetic acid (TFA) provided the best sensitivity (Fig. 4). The addition of trifluoroacetic acid in sheath liquid provided an acidic environment for high-sensitivity detection of triazine molecules. Under the optimal conditions, the on-line CZE-ESI-MS analysis of eight triazines is shown in Fig. 5. The $[\mathrm{M}+\mathrm{H}]^{+}$ion of each compound was selected for real-time monitoring. As expected from CE-UV study (Fig. 2a), only four peaks were observed in the total-ion current electropherogram and the third and fourth peaks were broader than the first two peaks. The elution order of the triazines in the third and fourth peak could not be assigned because of the poor time resolution (Fig. 2a). By using the mass spectrometer as the detector, the migration orders of these triazines could be determined easily (Fig. 5). The elution order was

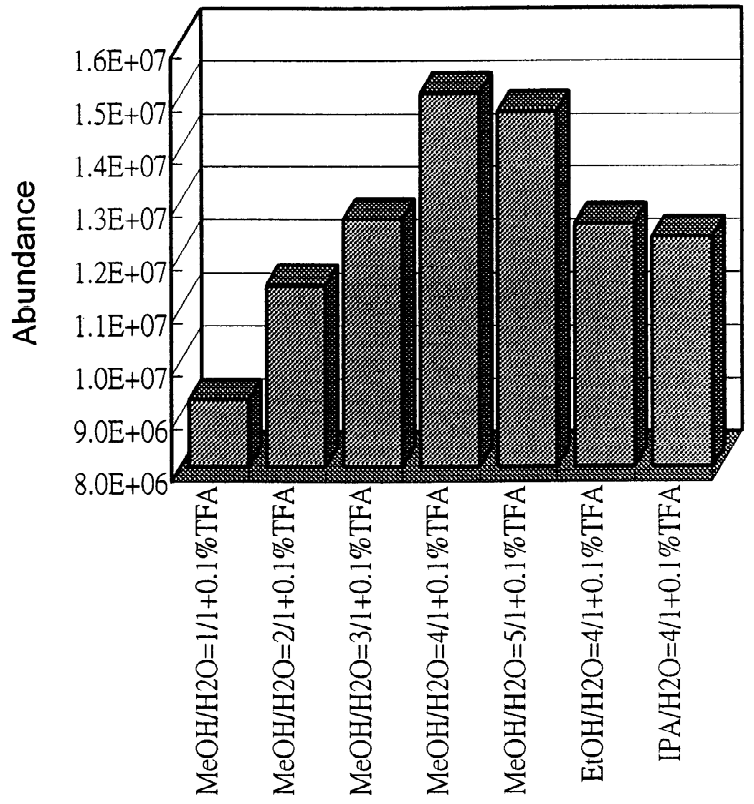

Fig. 4. Ion abundance as a function of ESI sheath liquid composition. The atrazine $(5 \mathrm{mg} / \mathrm{l})$ was electroosmotically infused $(20 \mathrm{kV})$ through the silica capillary. found to be prometryn (19.11 min), ametryn (19.18 min), and simetryn (19.36 min) for the third peak and propazine $(23.27 \mathrm{~min})$, atrazine/simazine (23.34 min.) for the fourth peak. Another advantage of using MS detection is that there is no overlap in the mass electropherograms making the quantitative analysis more reliable.

Although the uncertainty in triazine identification in normal EOF CE was reduced significantly by using the mass spectrometer as the detector, the quality of identification could be further improved if triazines were analyzed by reversed EOF CE-ESIMS. Under this condition, triazines are differentiated both in retention time and in molecular mass. Initially, the sheath liquid used in normal CE (methanol-water, 80:20) containing $0.1 \%$ TFA) was adopted for reversed EOF CE-ESI-MS approach. Unfortunately, the resolution was much poorer than the one obtained with UV detection. Similar phenomenon was observed in CE-UV if the buffer solution in the anode was replaced with sheath liquid. The result of this CE-UV experiment suggested that the sheath liquid played an important role for the degradation of $\mathrm{CE}$ resolution. Because the $\mathrm{pH}$ of the sheath liquid is lower than the running buffer for better ionization efficiency, the poor CE-MS resolution is more likely due to the migration of proton from sheath liquid into the separation column. The effect of sheath liquid on the formation of the moving ionic boundary has been reported by Karger [34]. The quality of the electropherogram improved significantly when TFA was replaced with ammonium acetate in the sheath liquid. The SIM electropherogram obtained with $90 \%$ methanol-water (80:20) and $10 \% 50 \mathrm{mM}$ ammonium acetate buffer, $\mathrm{pH} 3.85$ as the sheath liquid is shown in Fig. 6. Triazines were identified by their retention time and molecular mass. One disadvantage of the reversed EOF CE-MS approach is that the sensitivity is poorer than normal CE-MS because of the limitation of using sheath liquid of higher $\mathrm{pH}$.

\section{Conclusion}

Normal EOF CE was not able to resolve the eight triazines. The method of dynamic coating with 


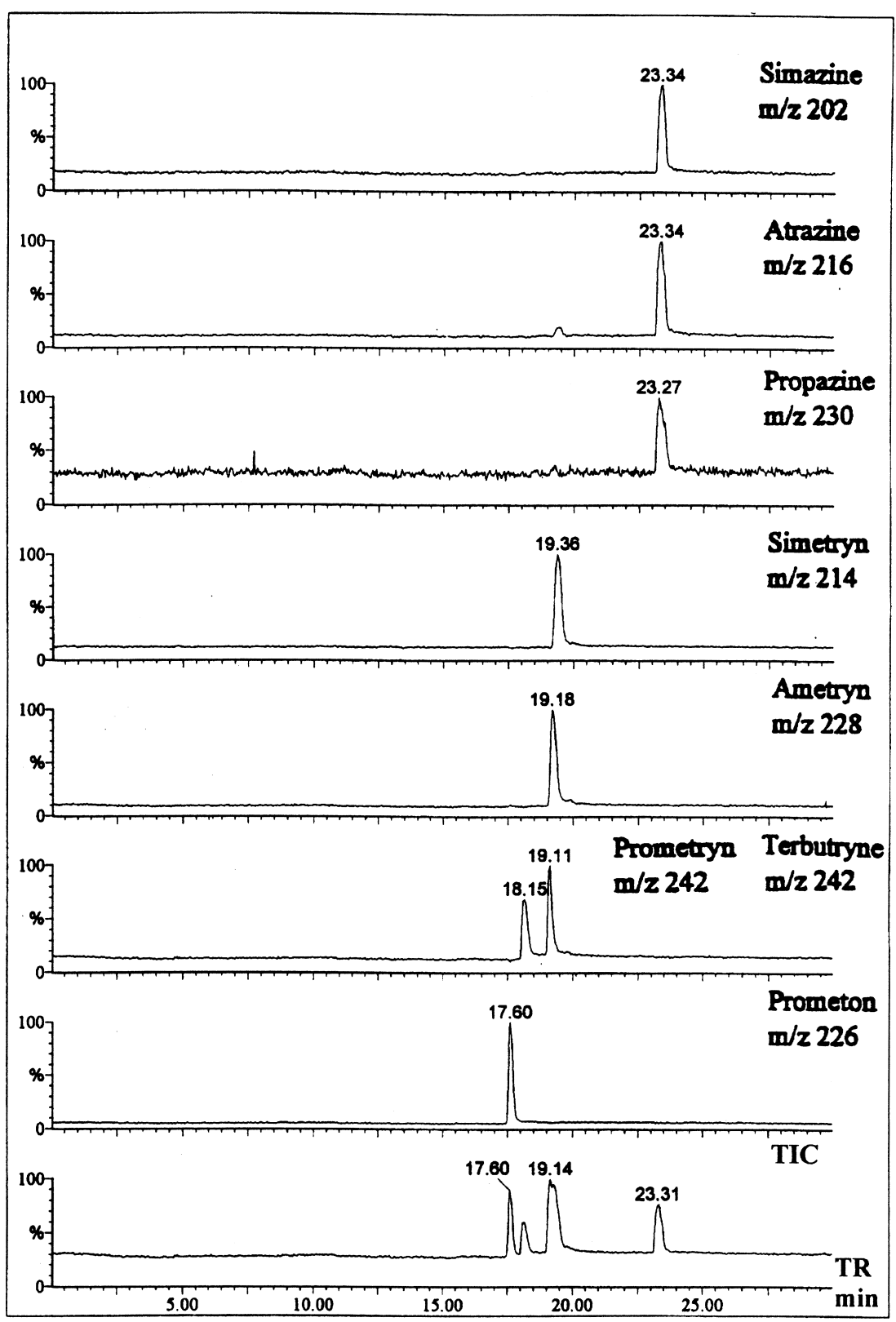

Fig. 5. Selected-ion electropherograms of triazines by normal EOF CE-MS. Sheath liquid composition was methanol-water (80:20) containing $0.1 \%$ TFA. Other conditions were the same as in Fig. 2a. TR=Migration time.

CTAB surfactant in the buffer induces the reverse of EOF and enables the separation of all eight triazines. The on-line coupling of CE and MS provided an excellent analytical tool for the separation and identification of triazines. Although baseline resolution was not obtained with normal $\mathrm{CE}$, the use of 


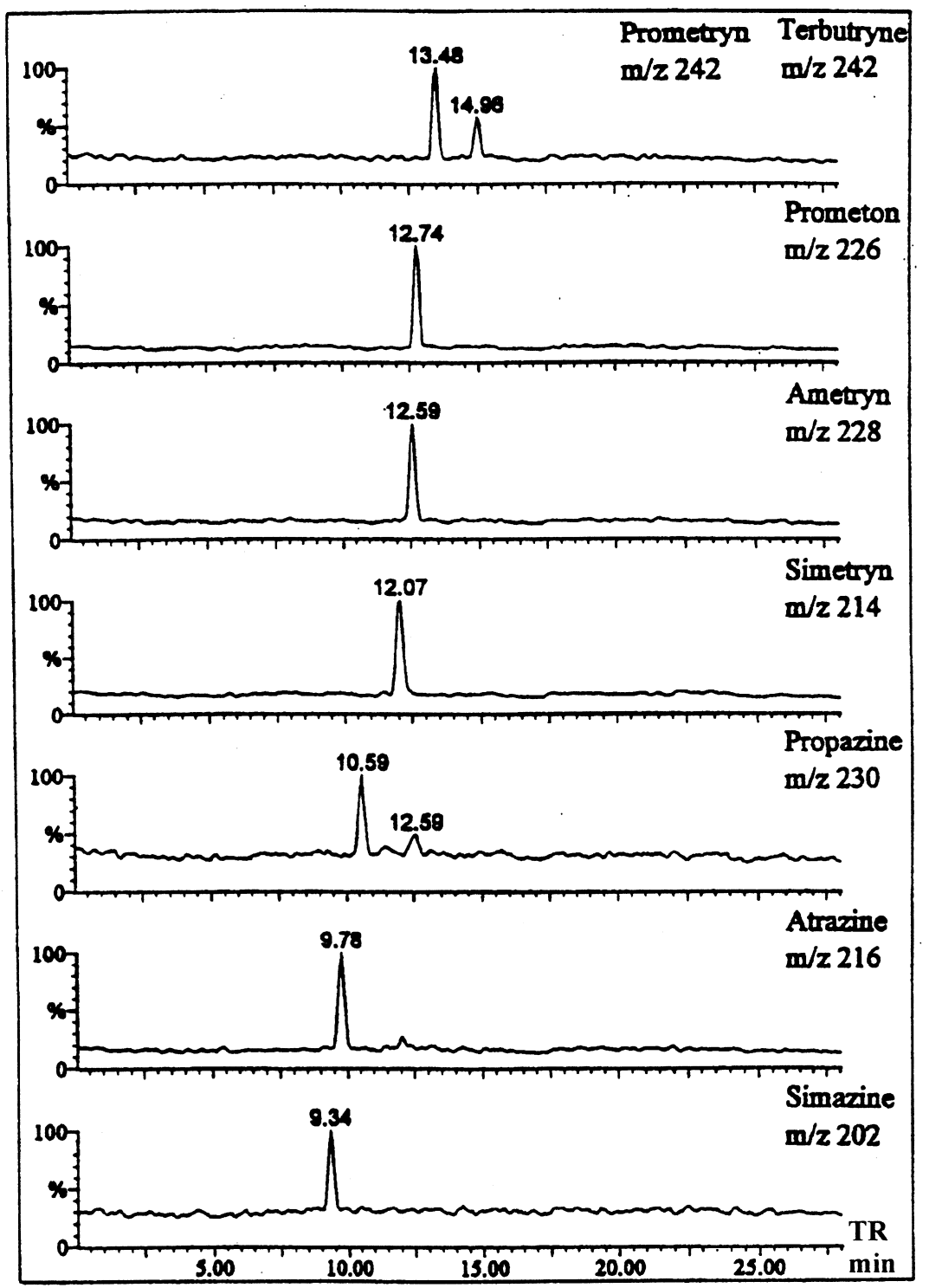

Fig. 6. Selected-ion electropherograms of eight triazines by reversed EOF CE-MS. Sheath liquid composition was $90 \%$ methanol-water $(80: 20)+10 \% 50 \mathrm{mM}$ ammonium acetate at $\mathrm{pH} 3.85$. Other conditions were the same as in Fig. $2 \mathrm{~b}$. The additional peak at $12.59 \mathrm{~min}$ with $\mathrm{m} / \mathrm{z} 230$ was the $\mathrm{M}+2$ isotope peak ( $\mathrm{S}$ atom) of ametryn.

ESI-MS as the on-line detection method significantly improved the quality of compound identification. Reversed EOF CE-MS provided a better result than normal EOF CE-MS. Under these conditions, triazines were identified both in retention time and in molecular mass. The composition of sheath liquid is more critical in reverse EOF CE-MS than in normal EOF CE-MS. The limitation(s) of using sheath liquid with similar $\mathrm{pH}$ and/or composition as running buffer is under investigation. It is hoped that a 
solution can be found so that resolution and sensitivity can be achieved simultaneously.

\section{Acknowledgements}

This work was supported by the National Research Council of Taiwan.

\section{References}

[1] F. Foret, V. Sustaek, P. Bocek, Electrophoresis 11 (1990) 95.

[2] G. Karlaganis, R.V. Arx, H.U. Ammon, R. Camenzzind, J. Chromatogr. 549 (1991) 229.

[3] G. Acchero, S. Apone, C. Sarzanini, F. Mentasti, J. Chromatogr. A 668 (1994) 365.

[4] J.C. Molto, Y. Pico, G. Font, J. Manes, J. Chromatogr. 555 (1991) 137.

[5] G. Sacchero, C. Sarzanini, F. Mentasti, J. Chromatogr. A 671 (1994) 151.

[6] J. Sheran, J. Liq. Chromatogr. 9 (1986) 3433.

[7] V. Lopez-Avila, P. Hirata, S. Kraska, M. Fiangagan Jr., J.H. Taylor, S.C. Hern, Anal. Chem. 57 (1985) 2707.

[8] S.A. Schaette, R.G. Smith, L.R. Holden, J.A. Grahan, Anal. Chim. Acta 236 (1990) 141.

[9] Z. Cai, V.M.S. Ramannjam, D.E. Giblin, M.L. Gross, Anal. Chem. 65 (1993) 21.

[10] I. Hammond, K. Mooro, H. James, C. Watters, J. Chromatogr. 474 (1989) 175.

[11] H. Persen, L. Zupancic-Krali, J. Marsel, J. Chromatogr. A 704 (1995) 121.

[12] P. Schmitt, A.W. Garrison, D. Freitag, A. Kettrup, J. Chromatogr. A 723 (1996) 169.

[13] C. Desiderio, S. Fanali, Electrophoresis 13 (1993) 698.

[14] G. Dinelli, A. Bonetti, P. Catizone, G.C. Galletti, J. Chromatogr. B 656 (1994) 275.
[15] R. Carabias Martinez, E. Rodriguez Gonzalo, A.I. Munoz Dominguez, J. Dominguez Alvarez, J. Hernandez Mendez, J. Chromatogr. A 733 (1996) 349-360.

[16] A. Farran, S. Ruiz, C. Serra, M. Aguilar, J. Chromatogr. A 737 (1996) 109-116.

[17] W.M. Nelson, C.S. Lee, Anal. Chem. 68 (1996) 3265-3269.

[18] Ph. Schmitt, D. Freitag, I. Trapp, A.W. Garrison, M. Schiavon, A. Kettrup, Chemosphere 35 (1997) 55-75.

[19] M. Nelson, Q. Tang, A. Harrata, C.S. Lee, J. Chromatogr. A 749 (1996) 219-226.

[20] L. Yang, A.K. Harrata, C.S. Lee, Anal. Chem. 69 (1997) 1820-1826.

[21] M.A. Mosely, L.J. Deterding, K.B. Tomer, J.W. Jorgenson, Rapid Commun. Mass. 3 (1989) 87.

[22] M.A. Mosely, L.J. Deterding, K.B. Tomer, J.W. Jorgenson, J. Chromatogr. 516 (1990) 167.

[23] C.Y. Tsai, G.R. Her, J. Chromatogr. A 743 (1996) 315.

[24] T. Kaneta, S. Tanaka, M. Taga, J. Chromatogr. A 653 (1993) 313.

[25] S. Terabe, K. Ishikawa, K. Utsuka, A. Tsuchiya, T. Ando, Proceedings of the 26th International Liquid Chromatography Symposium, Kyoto, 25-26 January, 1983.

[26] B.B. VanOrman, G.L. McIntire, J. Microcolumn Sep. 1 (1989) 289.

[27] T.J. Kasper, M. Melera, P. Gozel, R.G. Brownlee, J. Chromatogr. 458 (1988) 303.

[28] S.M. Masselter, A.J. Zemann, Anal. Chem. 67 (1995) 1047.

[29] J.A. Loo, H.R. Udseth, R.D. Smith, Rapid Commun. Mass Spectrom. 2 (1988) 207.

[30] R.D. Smith, J.A. Loo, C.J. Barinaga, Rapid Commun. Mass Spectrom. 4 (1990) 54.

[31] R.D. Smith, J.A. Loo, C.J. Barinaga, C.G. Edmonds, H.R. Udseth, J. Am. Soc. Mass Spectrom. 1 (1990) 53.

[32] E.D. Lee, W. Muck, J.D. Henion, T.R. Covery, Biomed. Environ. Mass Spectrom. 18 (1989) 144.

[33] A.P. Bruins, T.R. Covery, J.D. Henion, Anal. Chem. 59 (1987) 2642.

[34] F. Foret, T.J. Thompson, P. Vouros, B.L. Karger, P. Gebauer, P. Bocek, Anal. Chem. 66 (1994) 4550. 